\title{
Assessment of Green Public Procurement as a Policy Tool: Cost-efficiency and Competition Considerations ^
}

\author{
Runar Brännlund • \\ Department of Economics at Umeå University \\ Umeå University \\ SE-901 87Umeå, Sweden \\ runar.brannlund@econ.umu.se \\ Sofia Lundberg* \\ Department of Economics at Umeå University \\ Umeå University \\ SE-901 87Umeå, Sweden \\ sofia.lundberg@econ.umu.se \\ Per-Olov Marklund \\ Center for Regional Science at Umeå University (CERUM) \\ Umeå University \\ SE-901 87 Umeå \\ per-olov.marklund@econ.umu.se
}

\begin{abstract}
Public procurement is officially regarded as an effective means to secure environmental improvement. Estimates by the European Commission indicate that public authorities within the European Union typically purchase goods and services corresponding to approximately 16 percent of GNP per annum. Hence, it is believed, private firms can be stimulated to invest in sustainable production technologies if the market power of public bodies is exerted through Green Public Procurement (GPP) policies. In this paper we assess whether GPP is a costefficient policy tool, and if so whether its implementation can, from a welfare perspective, deter or stimulate entry to procurement markets.
\end{abstract}

JEL-classification: H57, Q01, Q28

Key-words: Competitive Bidding, Cost-efficiency, Procurement auctions, Sustainability

\footnotetext{
- We thank participants in seminars at the Swedish Competition Authority (KKV) and the Department of Economics at Umeå University for valuable insights and comments. This paper also builds on a report written in Swedish directed towards practitioners and politicians written on behalf of the KKV. We thank the Authority for giving us that assignment.

- Financial support from the Swedish Energy Agency is gratefully acknowledged.

* Corresponding author, email: sofia.lundberg@econ.umu.se.
} 


\section{Introduction}

For many countries globally, public procurement represents a significant proportion of the economy. Notably, estimates indicate that public authorities in the European Union (EU) purchase goods and services corresponding to approximately 16 percent of the EU's annual Gross Domestic Product (GDP) (COM, 2008). ${ }^{1}$ For a national example, in 2006 the Swedish authorities purchased goods and services totaling between 450 and 535 billion SEK, which corresponds to 15-18 percent of annual GDP (Bergman, 2008). Because of their considerable purchasing power, public authorities are often regarded as having the power to promote sustainable development by stimulating (or demanding) the use of more energy efficient, less polluting production techniques and renewable resources. This paper assesses public procurement standards as a policy tool to encourage sustainable development.

Public procurement, or in the context of sustainability, Green Public Procurement (GPP), is officially regarded as an internationally important, flexible and powerful policy instrument. The Europe an Commission (EC) has emphasized the importance of cost-efficient GPP (COM, 2008) and, in compliance with the EU's Integrated Product Policy (IPC), Member States have been encouraged to devise national action plans. Accordingly, the role that environmental criteria play in procurement has grown in importance, at both national and EU levels. In 2004 the EC published a handbook with the clear aim to help public authorities to implement GPP (European Commission, 2004). The EC appears to be very clear in its ambition of how GPP can contribute to sustainability.

However, the credit given ex ante to GPP as a viable environmental policy tool has not been thoroughly academically validated. GPP and its impact in terms of both environmental effectiveness and cost-efficiency need to be further analyzed (Lundberg et al., 2008). This need is increased by the fact that the expectations of GPP are typical very high. Many governments and authorities rely heavily upon GPP as an accepted environmental policy instrument (as illustrated by the Swedish Government Bill 2008/09:162). Cost-efficiency and market competition are important aspects to consider when striving to achieve a sustainable soc iety. Consequently, the potential of GPP to contribute to the attainment of sustainable development should also be evaluated. The international literature in this field is limited,

\footnotetext{
1 The corresponding figure is 9 percent for the OECD countries during 1990-1997 (average total expenditure minus employee compensation as a percentage of GDP; Marron, 2003).
} 
particularly with respect to GPP in the context of welfare economics. Therefore, the major objectives of this paper are to identify and discuss general issues that need to be addressed when considering environmental criteria in public procurement, and the pros and cons of GPP within a framework of welfare economics. Questions considered being of particular importance for this research paper include whether GPP is a cost-efficient policy instrument and whether it affects competition in terms of the number of tenders made.

When considering GPP as an environmental policy tool it is important to remember the fundamental reasons for engaging in public procurement, since public authorities could simply provide all their services in-house, rather than through e xternal supp liers. However, by allowing private firms to compete for certain public provision contracts it is maintained that society gains by obtaining better value for money. The basic rationale is that competition stimulates innovation and encourages specialization. It would be very expensive to finance a public sector that was specialized in all areas for which it provided services, and competition in itself leads to lower prices (see Bergman, Nilsson, and Pyddoke, 2005). In this paper it is therefore argued that when GPP is implemented its effect on competition must be considered. Environmental gains could be offset by losses in efficiencies due to the restriction of competition. The implementation of GPP is a complex task and it also needs to be carefully adapted to take account of existing environmental policy tools that have already been applied to address environmental problems. Here, GPP is approached as either a complement to, or a substitute for, other types of environmental policy instruments. In this context it is important to compare different environmental policy instruments and their properties with respect to for example cost-efficiency.

The paper is structured as follows. In the following section the available academic literature is discussed in more detail. In Section 3, the institutional settings required for the implementation of GPP are outlined, together with its potential to create incentives for private industry to invest in more environmentally sustainable technologies. GPP in the context of cost-efficiency and its relationship with other environmental policy tools are discussed in Section 4. The importance of competition and relevant inter-related issues are considered in Section 5. Section 6 concludes the paper and provides a summary and analysis of the benefits and disadvantages of GPP. 


\section{Previous studies}

As an environmental policy tool, GPP has been little studied, particularly in the field of economics. Further, authors who have considered GPP have generally treated it as an established policy and either analyzed its effects on specific products and firms' costs (e.g., Marron, 1997; Sterner, 2002; Cerin, 2006; D’Amoto, 2006; Parikka-Alhola, 2008; Geng and Doberstein, 2008), or assessed case studies of the practical implementation of GPP (see Thomson and Jackson, 2007, for a UK example). None of the cited authors have questioned whether GPP is an adequate environmental policy tool or considered how it should be assessed. Certain other authors have been more prescriptive, arguing that since public authorities have considerable market power, they should implement GPP by making ecolabeling mandatory when formulating environmental procurement criteria (Grolleau et al., 2004). In addition, the wider question of how to make local government budgets greener has been addressed in a book edited by Clinch et al. (2002). Here, the concept of making budgets greener covered the role of subsidies as well as public purchasing at local government level. The research was generally descriptive in nature and, once again, the question of whether GPP should be viewed as a complement to, or a substitute for, other types of environmental tools was not highlighted.

Furthermore, in analyzing GPP as an environmental policy tool it is informative but not sufficient merely to report changes in the use of environmental criteria in public procurement contracts (in terms of degree and frequency), which is the approach adopted by Nissinen et al. (2009) and Kippo-Edlund et al. (2005). Neither of those studies posed the critical questions regarding the appropriateness of GPP as a welfare-enhancing policy tool, and how to implement it. The authors of the present paper maintain that, from the perspective of costefficiency and market competition, GPP has not been well studied and this research contributes to the available literature in these respects.

\section{Implementing GPP}

Following EU procurement directives (Directive 2004/17/EC and Directive 2004/18/EC), the inclusion of environmental requirements in public procurement contracts are deemed to be 
valid as long as they do not discriminate firms from submitting a tender. ${ }^{2}$ Briefly, the EU directives stipulate sealed bidding for public contracts, which can subsequently be awarded according to either of two principles. Contracts are awarded either to the supplier who has submitted the lowest price bid or to the supplier considered to have submitted the most economically advantageous bid. When a proc uring entity publishes a call for tender it must state the principle that will be applied to evaluate bids. A contract assignment that must conform to the principle of the most economically advantageous bid means that, in addition to price, weight is also given to other criteria such as environmental aspects. The environmental criteria and the means by which such criteria will be evaluated against quality and price must be specified in the call for tender. ${ }^{3}$ By specifying environmental criteria the procuring entity is enforcing GPP. Irrespective of the assignment principle, the winning firm is paid in accordance with its bid. Under both principles the procedures for bid evaluation and the assignment of contracts are regulated by the directives. If price is the sole factor determining which firm is contracted, the bid is said to be "one dimensional". If additional criteria are specified when the contracts are assigned, the bids are termed "multidimensional". For simplicity, it is assumed here that the bids are two-dimensional, meaning that two criteria are applied; price and environmental aspects. ${ }^{4}$ The environmental dimension can take the form of eco-labeling, environmental standards, technical standards, material specifications, requirement of specific processes and production methods, and/or performance-based specifications. The criteria may include clauses that oblige bidding firms to change their production technology in order to meet the public procurement requirements.

The environmental criteria may be mandatory, obliging the firm to demonstrate its ability to satisfy them in order to be considered as a qualified bidder. Such criteria can have varying degrees of stringency. However, environmental criteria may also be recommended, rather than obligatory. Again, in such cases criteria can have varying degrees of stringe ncy. Furthermore, regardless of whether they are mandatory or recommended, weights can be assigned to environmental criteria relative to the price of the procured goods or services. This

\footnotetext{
2 The EU directives stipulate five principles to be followed by procuring entities. These are the principles of mutual recognition, proportionality, transparency, equal treatment, and non-discrimination. The common denominator of these principles is that tenders, or their bids, should be assessed under conditions of effective competition.

3 An overview and discussion of different models for evaluating bids according to price and quality criteria is presented by Anderss on and Lunander (2004).

${ }^{4}$ In reality several types of criteria related to quality aspects, such as references and competence, can be listed and weighed against price.
} 
gives the procuring entity an opportunity to tailor its implementation of GPP in several ways and to decide the relative importance of environmental sustainability and product price. That is, the procuring entity can combine environmental criteria ranging from low to high stringe ncy, with low to high weights attributed to specified criteria. A typical example of a weak criterion would be eco-labeling of some kind, which is generally fulfilled by all firms in a market. As indicated in Table 1, the design of a GPP contract will determine its potential to

promote environmental sustainability. Application of weak environmental criteria in combination with the assignation of low weights to these factors will create little or no need for firms to invest in more environmentally friendly technologies in order to fulfill the criteria, and as such will have little or no effect on sustainability.

When the environmental criteria are weighted against price, contracts are assigned according to the most economically advantageous bid. However, using the principle of lowest price does not rule out the option to implement GPP. Procuring entities can specify environmental criteria that are mandatory and award the contract to the lowest bidding firm that can fulfill the criteria. Again the criteria can range from low to high levels of significance.

[Table 1 about here]

When environmental criteria are selected and formulated by the procuring entity, several factors must be considered to ensure the functioning of GPP. Primarily, the criteria should be adapted to the environmental problems associated with the purchases made to fulfill the GPP contract. In addition, if other environmental policy tools are already in force, such as a tax or fee, then the GPP must complement them. Furthermore, cost efficiency must be considered when evaluating GPP. Finally, its effect on market competition must also be carefully evaluated. These considerations are discussed in the following sections, starting with costefficiency and followed by market-oriented aspects, such as the impact of GPP on competition and the relative importance of the procuring entity in the market.

\section{GPP and cost efficiency}

This section compares GPP to other environmental policy measures, assesses cost-efficiency and evaluates whether GPP fulfils the environmental objectives. 


\subsection{GPP ve rsus ot her envi ronmental policy meas ures}

GPP should be considered as an administrative (or quantitative) environmental policy tool. Administrative tools can be implemented by the command and control approaches to environmental management, which can include the specification of maximum allowed emissions and detail the requirements of products, production processes or technologies. All these measures have a common aspect in that they are not usually cost-efficient. More specifically, their implementation does not generally lead to the cost-minimized allocation of resources used to achieve a specified target. In the context of GPP, this could be attributed to the procuring entity having incomplete information about all potential suppliers, their products and production technologies, and also not being aware of all available production technologies. In GPP, command and control style requirements for products, production processes, and technologies are commonplace. Requirements may cite the need, for example, to use a specific technology in the production of a procured product, or to use certain products that do not contain specified hazardous substances when supplying a procured service. However, a major problem in a cost-efficiency perspective of the command and control approach is that it contains no inherent mechanism to ensure that producers who could abate pollution at the lowest cost do so (Perman et al., 1996, p.223-226). This can be argued to be valid for GPP, as a call for tenders will specify exactly the same environmental requirements for all potential bidders, but of course imposes no restrictions on firms who do not bid.

An alternative approach to environmental control is the use of economic tools, such as taxes, subsid ies and tradable permits. Taxes and subsidies impact upon emission levels ind irectly via the price mechanism. Tradable permits work in terms of regulated quantities, similar to the administrative policy tools described above. However, in this case a market is established in which permits may be traded at a certain price and a relative price is established between a permit and a marginal emission reduction. This will create essentially the same economic incentive to adjust environmentally as in the case of, e.g., a tax (Perman et al., 1996, p. 226229). As demonstrated in the following section, economic policy tools are automatically costefficient, because all producers in the market will adjust their productions technology until they achieve the same marginal cost of reduction, even though no two producers may be alike. 


\subsection{Cost-efficiency - What does it mean in the context of GPP?}

The fundamental point of environmental policy is that it should encourage resources to be allocated in such a manner that welfare is maximized. Therefore, economically efficient environmental policy centers on the satisfaction of two conditions (see, e.g., Perman et al., 1996, p. 220). Firstly, given perfect information concerning pollution quantities and their environmental impact, environmental objectives must be optimized. Formally, this entails that a socially optimal objective is achieved when the be nefit of additional environmental control balances the cost of implementing this additional control. Secondly, the environmental objectives must be achieved at least cost. If these two efficiency conditions are met, resources, including environmental resources, are allocated in a manner that maximizes welfare. However, it is unrealistic to assume that public bodies will have perfect information (as assumed above), and thus it is unreasonable to assume that they can price environmental resources precisely. Therefore, from a social welfare perspective, it is almost impos sible to establish optimal environmental objectives. Instead, desired environmental objectives are established, and the cost-efficiency condition should be the guiding rule in achieving these objectives (Perman et al., 1996, p. 217). ${ }^{5}$

When evaluating GPP as an environmental policy tool it is important to consider costefficiency and what this term actually means. As a simple example, assume that an environmental problem originates from polluting firms that are different in terms of production technologies, and that the authorities are about to decide upon a pollution reductions target. Furthermore, assume that no other environmental policy tools are currently being applied to address this particular problem. Ideally, the authority should implement a policy tool that leads to the reduction of pollution in a cost-efficiently manner. However, if the polluters use different technologies they will also differ in the required reduction of their emitted pollutant loads. This means that when the environmental objective is achieved costefficiently, i.e., when the marginal cost of reduction between firms is identical, they will have reduced their pollutant loads by differing amounts. This is illustrated for a two firm case in Figure 1.

\footnotetext{
${ }^{5}$ Note that this means that cost-efficient environmental policy does not necessarily lead to imp roved overall social welfare. If the environmental target is set incorrectly the environmental policy measure may not contribute to sustainability even if it is cost-efficient.
} 
[Figure 1 about here]

For simplicity, assume that there are only two firms (A and B) that use different production technologies, and hence differ in their pollution reduction costs, as illustrated by the different marginal cost curves, $M C_{A} \neq M C_{B}$, shown in the figur e. Note that it is the marginal cost for pollution abatement that is illustrated. Furthermore, assume that the government decides to impose a tax, $t$, per unit of pollution that corresponds to society's desired pollution reduction target, $z^{S}$. Inherent in the tax mechanism is the impetus for both firms to reduce their pollution optimally in terms of cost-efficiency (i.e., at lowest cost), which means that the following condition will be satisfied:

$$
M C_{A}^{1}=M C_{B}^{1}=t
$$

As a consequence, firm A will reduce its level of pollution less than firm $\mathrm{B}$, since $z_{A}^{1}<z_{B}^{1}$. In the cost-efficient outcome the firms’ pollution levels will also sum to society's desired level. In the general case this means that:

$$
\sum_{i=1}^{n} z_{i}=z^{S} \quad \text { where the number of bidders is } i=1, \ldots, n
$$

GPP can then be analyzed from the perspective of cost-efficiency. Furthermore, GPP often stipulates environmental criteria in terms of command and control style specifications, e.g. specifying the adoption of a certain technology or the use of certain materials. Hence the fulfillment of environmental requirements results in homogenous producers. Therefore, when bidding firms have adjusted their production processes to accommodate the contractual environmental requirements of a GPP tender, they utilize the same production technology and therefore emit the same levels of pollution. As illustrated below, whether or not GPP reduces pollution cost-efficiently will depend on whether firms are initially homogeneous in production technology or not.

Assume that two firms (A and B) are bidding for a public contract. Initially, they are homoge neous in terms of their production technology so their marginal cost curves for pollution abatement are identical, $M C_{A}=M C_{B}$. Assume further that the procuring entity 
applies GPP, and that the environmental criteria are set such that the socially desired level of pollution $\left(z^{S}\right)$ will be reached if all firms adjust their production processes in accordance with the required environmental standards. Since the environmental criteria are identical for all bidders, their pollution reduction will in the general case also be identical, $z_{i}=z^{S} / n$. As illustrated in Figure 2, if both firms make the necessary investment to satisfy the bid's requirements, cost-efficiency will be reached, $M C_{A}^{1}=M C_{B}^{1}$, and each firm reduces their pollution by $z_{A}^{1}=z_{B}^{1}$. So, given initially identical production technology among bidding firms, GPP can be cost-efficient.

[Figure 2 about here]

Next, assume instead that firms are initially heterogeneous in terms of production technology, and that GPP is implemented in the same manner as described above. This will mean that some firms may need to undertake only minor adjustments in order to satisfy the tender's technological requirements while others may need to do considerably more. Therefore, their adjustment costs, i.e., their reduction costs, may differ substantially. In the two firm case this is reflected by differences in their marginal cost of reduction curves, $M C_{A} \neq M C_{B}$. As illus trated in Figure 3, the imposition of identical environmental criteria on all bidding firms will again result in equal pollution levels after they have made the necessary investments in order to fulfill the criteria, $z_{A}^{1}=z_{B}^{1}$. However, although a socially desirable level of pollution is reached, see expression (2), the cost-efficiency condition is not satisfied since $M C_{A}^{1}>M C_{B}^{1}$.

Furthermore, if at least one of the potential bidders decides not to participate in the procurement auction, because it does not expect the benefits to outweigh the costs of investment, then the total sum of the bidding firms' pollution levels will not equal the socially desirable level of pollution. In this case, not only is the implementation of GPP costinefficient, it miss-out the environmental objectives.

\section{[Figure 3 about here]}

If GPP is to work cost-efficiently in practice, the procuring entities will need to be highly competent in specifying their environmental requirements, and highly aware of the flow and quality of information in society. The simple scenario outlined above indicates that the 
procuring entity needs to know the differences between every single producer when formulating the call for a public tender. In theory, the public authority needs to know the cost of reduction function for every one of its prospective entrepreneurs. If the pollution reduction target is to be achieved correctly, this will involve different firms adjusting their processes accordingly, so that they meet the authority's contractual specifications. Therefore, the public tender process will place differing demands on interested firms, depending on the extent of investment needed to comply with the GPP contract. Exactly the same demand cannot be made for all firms in the tender contract. Of course, cost-efficiency is even more complicated and difficult to attain if the procurement entity has to consider the complete environmental life cycle (i.e., life cycle analysis) for each product it puts out to public tender, as is often the case in reality. 


\subsection{GPP or economic instruments - Goal-fulfillment or cost-efficiency?}

As previously concluded, perfect information is essential for administrative environmental policy tools, such as GPP, to work cost-efficiently. However, the cost of obtaining perfect information is extremely high (infinite) and procuring entities are therefore forced to formulate calls for tenders based on incomplete information. ${ }^{6}$ Hence, GPP will never resolve environmental problems cost-efficiently in practice. Furthermore, it is important to note that the cost-efficiency condition should also include related costs, such as monitoring, administration, and the resources needed to persuade producers to adjust their process technologies to accommodate the requirements of the policy instrument in question. However, the appropriate choice of environmental policy instrument, e.g. a tax or GPP, should not always be solely based on cost-efficiency.

Incomplete information will also affect the results of using economic policy instruments, such as an environmental tax on ind ustrial emissions. Since the regulating authorities do not know every producing firm's cost of reduction function, it is difficult to know in advance how large an emission reduction a specific tax rate will lead to (Bamoul and Oates, 1988). This means that a cost-efficient policy tool may be associated with uncertainty, and may therefore be inefficient in terms of goal-fulfillment. ${ }^{7}$ If a tax is introduced at too low a rate, then its full environmental objective will not be realized. In response to such an outcome, the tax rate may be increased, but the delay entailed in reaching the appropriate level may result in considerable damage to the environment. In this regard, administrative tools, such as specifying technological requirements, can be more efficient in terms of goal-fulfillment because large emission reductions can be achieved relatively quickly (Perman, 1996, p. 226). This approach is especially valid if 'green' technologies are already available on the market but not yet commonly adopted, and this could be one argument in favor of GPP. F urthermore, there is the possibility of combining administrative and economic environmental policy instruments, e.g. environmental taxes and GPP. The selection of a suitable policy instrument, when dealing with uncertainty is not a trivial issue because the preferred choice will depend on the specific environmental problem and its mitigation costs. As first shown by Weitzman

\footnotetext{
${ }^{6}$ See Carlton and Perloff (2005).

${ }^{7}$ The particular uncertainty referred to does not concern tradable permits, because the number of permits that are distributed among polluting sources represents an environmental target measured as a quantity. However, in this case the uncertainty is associated with the price a permit should be set at.
} 
(1974), a useful "rule of thumb" may be that an administrative app roach is the best choice if the marginal damage of, for example, emissions rises sharply relative to the marginal abatement cost, whereas a price tool (e.g. a tax) may be preferable if the marginal abatement costs rise sharply relative to the marginal damage. Finally, another plausible reason for the tax rate being set too low compared to the environmental ambitions may be the political difficulties associated with burden of taxation. In this situation, it may be politically easier to manage environmental objectives by adopting joint, complementary taxation and GPP policies.

A further debate regarding administrative versus economic environmental policy instruments concerns dynamic efficiency (Perman et al., 1996, p. 223-226). When private industry adjusts to economic policy tools, for example environmental taxes, it may encourage continued innovative behavior which affects both products and processes. In essence, economic instruments may impose stronger incentives for firms to adopt new cost-reducing technologies than more administrative forms of regulation. A simple reason for this is that a tax (or purchase of permits) not only imposes a pollution abatement cost, but also continues as a tax cost for the emissions which are still released to the environment (see, for instance, Milliman and Prince, 1989, Jung, 1996, and Porter and van der Linde, 1995). A hypothesis is therefore proposed that these tools may be considered as continually stimulating technological development and productivity and hence moderating the initial cost increase. Porter and van der Linde (1995) extended this observation by claiming that environmental policy, when designed properly, ${ }^{8}$ improves dymic efficiency to such an extent that it more than offsets the initial cost imposed, and in fact improves competitiveness in the long term. This latter hypothesis, known as the 'Porter hypo thesis' is, however, difficult to confirm and has been completely rejected by empirical studies (Brännlund and Lund gren, 2009).

Whether GPP should be implemented, and to what extent, is continge nt on the environmental problem(s) that the policy is intended to address. This decision depends in part on the de gree to which the environmental externality associated with the public purchase is internalized (i.e. brought into economic decision-making) by other policy tools. The relationship between GPP and other environmental policy tools is summarized in Table 2, in three scenarios. (1) If the

8 According to Porter and van der Linde (1995), environmental regulations should include pollution taxes, deposit-refund schemes, and tradable permits. 
environmental externality caused by the production or consumption of the goods being purchased is not internalized, GPP could have a role to play. If all other environmental policy options have been considered and GPP is the best choice it should be implemented. However, it is then important to adapt GPP to ensure that it addresses the relevant environmental objectives. This entails carefully selecting the appropriate environmental criteria, and any weights attached to these specifications, to reflect both the externality caused by the purchase and the desired environmental objectives set by the government. (2) If the externality is partly internalized, GPP could play a role that complements the policy tools already in force. Again, GPP must be evaluated relative to other alternative environmental policy tools and optimized to match the required environmental objectives. (3) Finally, if the externality is fully internalized, GPP would do more harm than good from a welfare perspective and should not be implemented. Given the assumption that bids are either two dimensional or one dimensional, a consequence of the third outcome would be that contracts should only be awarded according to price. That is, bids should be one dimensional, meaning that no environmental criteria should be specified in the call for tender.

[Table 2 about here]

\section{GPP and competition effects}

In the auction literature (e.g. Vickrey, 1961; Laffont, 1997) it is well established that bids decrease with increasing numbers of bidders. For simplicity, one can assume a situation in which bids are one dimensional and the contract is awarded according to the lowest price. In such cases, the public procurement process takes the form of a first-price sealed bid auction in which homogenous bidders follow the equilibrium bid function: ${ }^{9}$

$$
\beta_{i}(c)=c_{i}+\frac{\int_{c}^{\infty}[1-F(u)]^{n-1} d u}{[1-F(c)]^{n-1}} \quad i=1, \ldots, n \text { bidders }
$$

${ }^{9}$ At equilibrium, each bidder assumes, correctly, that competitors act in accordance with the bidding rules described by the first-price, sealed bid auction. As a consequence, expression (3) is valid for all bidders. See McAfee and McMillan (1987). 
Here, $\beta_{i}(c)$ is the bid placed by bidder $i$, which is a function of the actual cos t for completing the contract, $c,{ }^{10}$ and the second term is the mark up, which is monotonically decreasing in $n$, the number of bidders. ${ }^{11}$ Differentiation of expression (3) with respect to $n$ will prove that the more bidders there are, the closer the bid will be to the cost, and the less profit the winning bidder will make. Empirical evidence of this competition effect on bid level is found, for example, in Gupta (2002) and Lundberg (2005). Even if bidders are assumed to be heterogeneous in cost, due to for example difference in production technology, bids are decreasing in $n$. From a welfare perspective, the de gree of competition is central to a maximizing outcome being reached. The more bidders there are for a tender, the closer the procurement auction will come to realizing the optimal welfare point for society.

In order to evaluate the total impact of implementing GPP on social welfare, its effect on market competition must be considered. The enforcement of GPP can be seen to impose an entry restriction upon potential entrepreneurs, thereby limiting competition. If firms are homoge neous in terms of production technology this will result in the procuring entity paying higher prices. In reality, however, production technology is rarely homogeneous among firms. If production technology is assumed to be heterogeneous instead, the effect on the degree of competition will vary. Specifying environmental criteria in public tender contracts could actually restrict entry of some firms but attract others to the procurement auction. For simplicity, it is assumed that there are two types of firms and that investment in environmentally friendly technology results in increases in both costs and bid prices, see expression (3):

Type A: Firms that have invested in environmentally friendly technology. The investment is driven by factors other than GPP being in force.

Type B: Firms that have not invested in environmentally friendly technology.

Based on the assumptions made above, type B firms will typically submit lower bids than type A firms, and if GPP is not in practice (bids are one dimensional) they will have a higher

\footnotetext{
${ }^{10}$ Theoretically, the cost, $c$, can be thought of as being drawn from a probability distribution with a cumulative distribution function $F(c)$, and different assumptions can be made about whether each firm's costs are independent, common, or linked to the costs of its competitors.

${ }^{11}$ The theoretical principles of the first-price sealed bid auction can, for example, be found in Milgrom (1989, 2004), Klemperer (1999, 2004), Krishna (2002), and Menezes and Monteiro (2005).
} 
probability of winning the contract. Being aware of this situation, type A firms will not participate in the auction. On the other hand, if the procuring entity practices GPP and bids are of a two dimensional nature, type A firms will enter the auction since they know their investments will be valued and therefore have a higher probability of winning. Type B firms face the following decision: to stay out of the procurement auction or make the investment required to meet the environmental criteria. The outcome of that decision will be determined by the expected pay-off from making the investment. If the potential benefits of investment outweigh the costs then type B firms will submit a bid, otherwise they will not. This leads us to three possible scenarios regarding the implementation of GPP and the degree of competition:

1. Positive effect: The number of Type A firms that enter the procurement auction exceeds the number of Type B firms that exit the market.

2. Negative effect: The number of Type B firms that exit the procurement auction exceeds the number of Type A firms that enter it.

3. No effect: The positive and negative effects cancel each other out.

Note that the effect on the degree of competition is separate from the effect of price. As a consequence of the assumptions made above (i.e., that meeting the environmental criteria will demand investment which affects costs), in expression (3) the outcome could be that bid prices are higher although more bids may be placed. The ultimate scenario that is observed in reality is entirely market-specific and of an empirical nature.

Overall, the implementation and effectiveness of GPP is revealed as being a complex task associated with important considerations ranging from cost-efficiency and the degree of market competition to price formation. The following section draws together the main research findings of this paper, and highlights the advantages and disadvantages of GPP in comparison to economic policy tools.

\section{Summary and discussion}


Firstly, GPP is not a cost-efficient environmental policy tool. All potential entrepreneurs considering a public tender under GPP face the same set of specified environmental criteria, although most of them have different types of production technology. Consequently, the outcome of GPP represents an equal reduction in pollution by all firms, which contravenes the cost-efficiency condition. In contrast to this, economic tools are seen to be sharper and automatically lead to cost-efficient outcomes. For example, a tax leads to the optimal reduction in pollution for each firm given their production technology. In this context, it is the mandatory nature of the environmental criteria that limits GPP from being cost-efficient.

Secondly, a major difference between economic tools (e.g. environmental taxes, subsidies, fees) and GPP is the decision-making/organizational structure responsible for these policy regimes. The decision-making and implementation of economic tools are generally centralized, but this does not apply to GPP. While national and local politicians may express an interest in applying GPP, the individuals who organize and implement it are the civil servants working in public authorities. Each procuring entity is represented by an agent who is by the political decisions obliged to implement GPP. Although all types of environmental policy tools face information problems, the extent of this problem is arguably greater for GPP due to the decentralized nature of its organization and decision-making process, which further reduces the probability of GPP operating cost-efficiently.

Another identified problem associated with GPP is its limited ability to create incentives for firms to invest in environmentally friendly production technology. If an environmental tax is levied, it will be imposed on all firms and as such cannot be avoided. In contrast, potential entrepreneurs can always choose not to submit bids to procurement auctions if they find the specified environmental criteria too expensive to fulfill. In this context, the scope for GPP to create incentives for firms to invest in sustainable production technologies is contingent on the producing entity being a sufficiently large and from the perspective of potential bidders interesting actor in the relevant market. If the procuring entity chooses to make purchases that are of great economic importance for firms, their incentives to meet the specified envi ronmental criteria are likely to be stronger. If not, GPP is substantially weakened as an environmental policy tool.

There are also characteristics of GPP that, under certain circumstances, could be argued to act in its favor. For example, the decentralized decision structure could be adva ntageous in some 
cases in comparison to economic tools. An economic tool such as a tax often considers environmental problems at an aggregated level, i.e. everybod y in the economy must pay the same tax rate. This means, inter alia, that the tax does not take into account the likelihood that pollution may have effects that vary in significance from one location to another. In such cases, the tax fails to account for the fact that the environment has varying sensitivity to pollutants depending on where the pollution occurs. GPP could serve as an instrument to consider such spatial variations, adjusting to local conditions, and could also account for differences in environmental preferences between local authorities. However, this approach places heavy responsibility on each and every procuring entity to maintain knowledge about the environment and how they interact with it locally. Note also that in this case the procuring entity should not pay attention to common (harmonized) criteria to be used when implementing GPP, e.g. suggested by the EC and national author ities.

Another possible advantage of GPP is that economic tools are typically limited by national boundaries. Taxes, for example, are generally decided at the national level and only target firms located within the nation's geographical boarders. GPP, on the other hand is borderless. Within the EU, for example, public contracts are open for firms in any of the Member States recognizing the single market. Hence, if a firm located in country A is interested in submitting a bid in a procurement auction or ganized in country B, the proc uring entity creates incentives for firms located outside the national boundary. Indeed, this option to create incentives for firms to invest in sustainable production technology is not limited by the EU boundaries. Again, the power to which this can be realized is contingent on the importance of the procuring ent ity as a buyer.

Compared to economic environmental policy tools, GPP may in some instances be relatively efficient in terms of fulfilling environmental objectives. For instance, as argued earlier, there may be political difficulties in levying a tax required to resolve a particular environmental objective. In such cases, by specifying that firms must adopt a specific technology, GPP may be more efficient in terms of satisfying environmental objectives, delivering large pollution reductions relatively quickly. This is especially valid if 'green' technologies are already available on the market that has not been widely adopted.

Finally, it is important to note that the effect of GPP on the degree of competition is separate from the effect on price. Implementing GPP could deter as well as stimulate entry. However, 
meeting the environmental criteria can demand investment costs and if so result in higher bids. As a consequence the outcome could be that bids are higher although more bids may be placed. Another plausible scenario is that bids are higher because fewer bids are placed due to GPP being seen as entry deterrence. The ultimate scenario that is observed in reality is entirely market-specific and of an empirical nature.

The main conclusion of this paper is that pursuing environmental policies via the implementation of GPP is a complex task. Although GPP is politically appealing as a policy measure and has some advantages, it is likely to be more efficient to use economic tools, such as taxes, subsidies, fees or emission permits. Finally, decisions about the implementation of GPP, as with any other policy tool, should be based on a welfare analysis, in which gains and losses are compared and only implemented when the net effect is beneficial. 


\section{References}

Andersson, A., and Lunander, A., 2004. Metoder vid utvärdering av pris och kvalitet i offentlig upphandling. En inventering och analys av utvärderingsmodeller inom offentlig upp handling. Konkurrensverkets uppdragsforskningsserie 2004:1.**

**Here, and elsewhere, in Swedish.

Baumol, W. J., and Oates, W. E., 1988. The theory of environmental policy. Cambridge University Press, Cambridge.

Bergman, M., Nilsson, J-E., Pyddoke, R., 2005. Den svåra beställarrollen. Om konkurrensutsättning och upphandling i offentlig sektor. SNS förlag, Stockholm.**

Bergman, M., 2008. Offentliga upphandlingar och offentliga inköp. Konkurrens verke t.**

Brännlund, R., and Lundgren, T., 2009. Environmental Policy without costs? A Review of the Porter Hypothesis, Umeå Economic Studies, No 766, Umeå University.

Carlton, D. W., and Perloff, J. M., 2005. Mode rn Industrial Organization. ass. Pearson Addison-Wesley, cop., Boston.

Cerin, P., 2006. Bringing Economic Opportunity into line with Environmental Influence: A Discussion on the Coase Theorem and the Porter and van der Linde Hypothesis, Ecological Economics, 56, 209-226.

Clinch, J. P., Schlegelmilch, K, Sprenger, R-U., and Triebswetter, U., 2002. Greening the Budget: Budgetary Policies for Environmental Improvement. Cheltenham: Edward Elgar. Series: International studies in environmental policy making

COM, 2008. Public Procurement for a Better Environment, Communication from the Commission to the European Parliament, The Council, The European Economic and Social Committee and the Committee of the Regions, COM(2008) 400 final. 
D’Amoto, A., 2006. Environmental Issues in Public Procurement: How Much Decentralization? Revista di Politica Economica, 96, 209-234.

Directive 2004/17/EC of the European Parliament and of the Council of 31 March 2004 coordinating the procurement procedures of entities operating in the water, energy, transport and postal services sectors (30.04.2004)

Directive 2004/18/EC of the European Parliament and of the Council of 31 March 2004 on the coordination of procedures for the award of public works contracts, public supply contracts and public service contracts (30.04.2004)

Geng, Y., and Doberstein, B., 2008. Greening Government Procurement in Developing Countries: Building Capacity in China, Journal of Environmental Management, 88, 932-938.

Government Bill, 2009, En sammanhållen klimat- och energipolitik - Klimat, Government Bill 2008/09:162.**

Grolleau, G., Mzoughi, N., and Nouira, C., 2004. Public Purchasing and Eco-labelling Schemes: making the Connection and Reinforcing Policy Coherence. Journal of Interdisciplinary Economics, 15, 131-151

Gupta, S., 2002. “Competition and Collus ion in a Government Procurement Auction Market.” Atlantic Economic Journal. 30, 13 - 25.

Jung, C., Krutilla, K., and Boyd, R., 1996. Incentives for Advanced Pollution Abatement Technology at the Industry Level: An Evaluation of Policy Alternatives. Journal of Environmental Economics and Management, 30, 95-111.

Milliman, S. R., and Prince, R., 1989. Firms incentives to promote technological change in pollution control. Journal of Environmental Economics and Management 17, pp. 247-265.

Kippo-Edlund, P., Hauta-Heikkilä, H., Miettinen, H., and Nissinen, A., 2005. Measuring the Environmental Soundness of Public Procurement in Nordic Countries, TemaNord 2005:505.

Krishna, V., 2002. Auction Theory. Academic Press, San Diego. 
Klemperer, P., 1999. "Auction Theory: A Guide to the Literature” Journal of Economic Surveys 13, 227-286.

Klemperer, P., 2004. Auctions: Theory and practice, Toulouse Lectures in Economics, Princeton University Press; Princeton and Oxford.

Laffont, J-J., 1997. "Game Theory and Empirical Economics: The Case of Auction Data." European Economic Review 41, 1-35.

Lundberg, S., Marklund, P-O., and Brännlund, R., 2008. Miljöhänsyn i offentlig upphandling - Samhällsekonomisk effektivitet och konkurrensbegränsande överväganden, Report written on behalf of Swedish Competition Authority (Summary in english).**

Lundberg, S., 2005. Restrictions on Competition in Municipal Competitive Procurement in Sweden. International Advances in Economic Research 11, 353-366.

Marron, D. B., 1997. Buying Green: Government Procurement as an Instrument of Environmental Policy, Public Finance Review, 25, 285-305.

McAfee, P. R., and McMillan, J., 1987. “Auctions and Bidding.” Journal of Economic Literature 25, 699-738.

Marron, D., 2003. Greener Public Purchasing as an Environmental Policy Instrument, in The Environmental Performance of Public Procurement: Issues of Policy Coherence. OECD.

Menezes, F. M., and Monteiro, P. K., 2005. An Introduction to Auction Theory. New York: Oxford University Press.

Milgrom, P. R., 1989. “Auctions and Bidding: A Primer.” Journal of Economic Perspectives 3, $3-22$. 
Milgrom. P., 2004. Putting Auction theory to work. Churchill Lectures in Economics, Cambridge; Cambridge University Press, New-York and Melbourne.

Nissinen, A., Parikka-Alho la. K., and Rita, H., 2009. Environmental Criteria in the Public Purchases above the EU Threshold Values by Three Nordic Countries: 2003 and 2005, Ecological Economics, 68, 1838 - 1849.

Parikka-Alhola, K., 2008. Promoting Environmentally Sound Furniture by Green Public Procurement, Ecological Economics, 68, 472-485.

Perman, R., Ma, Y., and McGilvray, J., 1996. Natural Resource and Environmental Economics, Longman Publishing, New York.

Pihl, H., 2007. Miljöekonomi - För en hållbar utveckling, Håkan Pihl och SNS Förlag, Stockholm.**

Porter, M. E., and van der Linde, C., 1995. Toward a New Conception of the EnvironmentCompetitiveness Relationship, Journal of Economic Perspectives, 9(4), 97-118.

SEC., 2004. Buying Green! A Handbook on Environmental Public Procurement. SEC, Commission Staff working document, (2004) 1050.

Sterner, E., 2002. 'Green Procurement' of Buildings: A Study of Swedish Clients' Considerations, Construction Management and Economics, 20(1), 21-20.

Thomson, J., and Jackson, T., 2007. Sustainable Procurement in Practice: Lessons from Local Government, Journal of Environmental Planning and Management 50(3): 421 - 444.

MSR, 2009. Swedish Environmental Management Council, Web Site, 2009-01-25.

Swedish Environmental Objectives Council, 2008. Sweden’s Environmental Objectives - In Brief...and a Summary of the Swedish Environmental Objectives Council’s Evaluation 2008. 
Vickr ey, W., 1961. “Counterspeculation, Auctions, and Competitive sealed Tenders.” Journal of Finance 16(1): 8 -37.

Weitzman, M. L., 1974. Prices vs. Quantities. The Review of Economic Studies, 41, 477-491. 


\section{Tables and Figures}

Table 1. The range of GPP outcomes due to different weighting and environmental criteria scenarios

\begin{tabular}{|l|l|l|l|}
\hline & \multicolumn{2}{|l|}{ Environmental criteria } \\
\hline & Low & High \\
\hline $\begin{array}{l}\text { Weight attached to } \\
\text { environmental crite ria } \\
\text { (relative to price) }\end{array}$ & Low & (1) None & (2) Effect on environment \\
\hline & High & $(3)$ Potential effect & (4) Stronger effect on \\
environment than (2)
\end{tabular}

Table 2. GPP - when and to what extent?

\begin{tabular}{|c|c|c|c|}
\hline & \multicolumn{3}{|c|}{$\begin{array}{l}\text { Degree to which the environmental problem (externality) that GPP } \\
\text { targets is internalized by other environ mental policy tools }\end{array}$} \\
\hline & $\begin{array}{l}(1) \\
\text { Not internalized }\end{array}$ & $\begin{array}{c}\text { (2) } \\
\text { To some extent } \\
\text { internalized }\end{array}$ & $\begin{array}{c}\text { (3) } \\
\text { Internalized }\end{array}$ \\
\hline GPP & $\begin{array}{l}\text { Yes, adapted to } \\
\text { relevant } \\
\text { environmental } \\
\text { quality objectives. }\end{array}$ & $\begin{array}{l}\text { Yes, as in (1), but } \\
\text { designed to } \\
\text { complement } \\
\text { policy tools in } \\
\text { force. }\end{array}$ & $\begin{array}{l}\text { No, given optimal and } \\
\text { internalized } \\
\text { environmental quality } \\
\text { objectives this is not } \\
\text { justifiable froma } \\
\text { welfare perspective. }\end{array}$ \\
\hline
\end{tabular}


Figure 1. Cost-efficient pollution reduction when a tax $(t)$ is imposed, that impacts the marginal cost (MC) of two firms (A and $\mathrm{B})$.

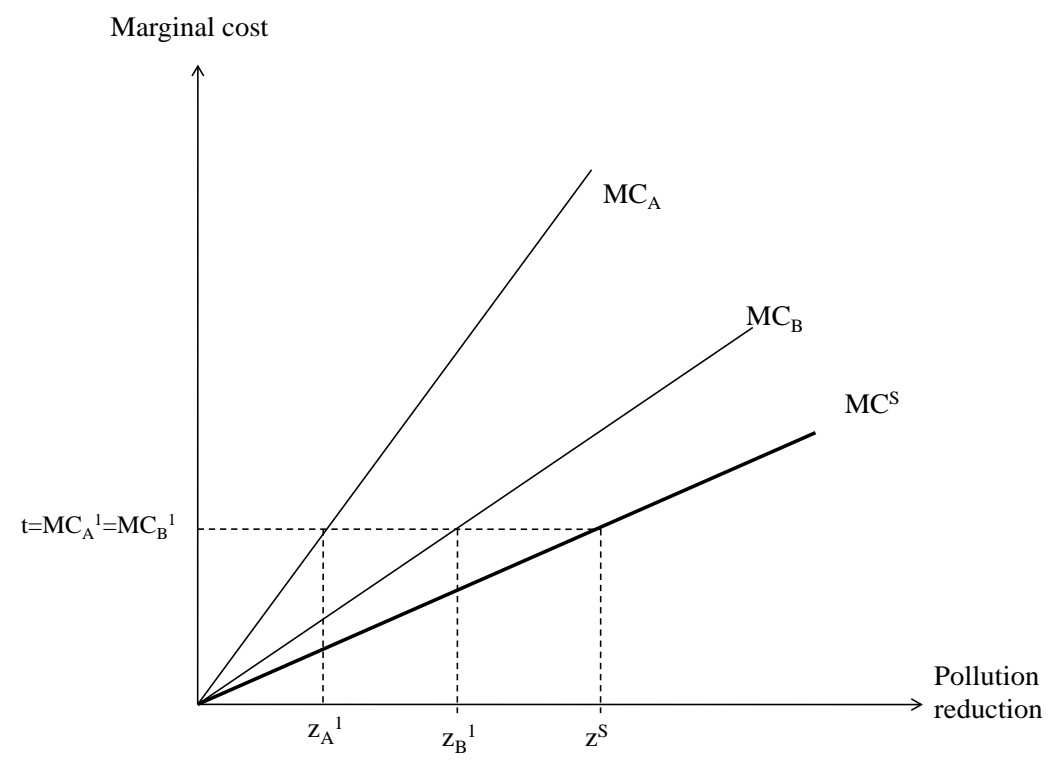

Figure 2. Cost-efficient pollution reduction when GPP is implemented and firms are homogeneous in terms of production technology (and hence their marginal cost, MC, curves are identical.

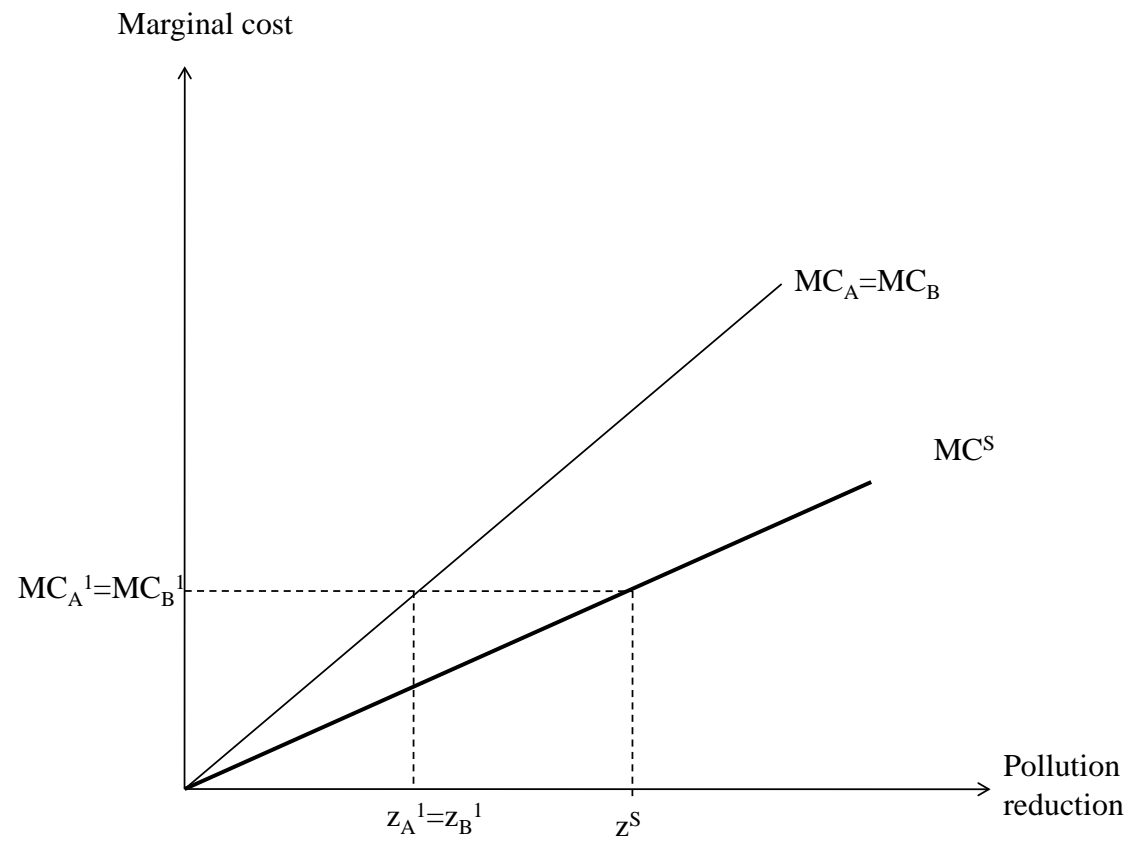


Figure 3. Cost-inefficient pollution reduction when GPP is implemented and firms are heterogeneous in terms of production technology (and hence their marginal cost, MC, c urves differ).

Marginal cost

$\mathrm{MC}_{\mathrm{A}}$

$\mathrm{MC}_{\mathrm{B}}$

$\mathrm{MC}^{\mathrm{S}}$

$\mathrm{MC}_{\mathrm{A}}{ }^{1}$

$\mathrm{MC}^{\mathrm{S}}$

$\mathrm{MC}_{\mathrm{B}}{ }^{1}$

Pollution

$\mathrm{z}_{\mathrm{A}}{ }^{1}=\mathrm{z}_{\mathrm{B}}{ }^{1} \quad \mathrm{Z}^{\mathrm{S}}$

reduction 